\title{
Microstructural Characterization of Ni/YSZ Electrodes in a Solid Oxide Electrolysis Stack Tested for 9000 Hours
}

Trini, Martina; Jørgensen, Peter Stanley; Hauch, Anne; Chen, Ming; Hendriksen, Peter Vang

Published in:

E C S Transactions

Link to article, DOI:

$10.1149 / 07801.3049$ ecst

Publication date:

2017

Document Version

Peer reviewed version

Link back to DTU Orbit

Citation (APA):

Trini, M., Jørgensen, P. S., Hauch, A., Chen, M., \& Hendriksen, P. V. (2017). Microstructural Characterization of $\mathrm{Ni} / Y S Z$ Electrodes in a Solid Oxide Electrolysis Stack Tested for 9000 Hours. E C S Transactions, 78(1), 30493064. https://doi.org/10.1149/07801.3049ecst

\section{General rights}

Copyright and moral rights for the publications made accessible in the public portal are retained by the authors and/or other copyright owners and it is a condition of accessing publications that users recognise and abide by the legal requirements associated with these rights.

- Users may download and print one copy of any publication from the public portal for the purpose of private study or research.

- You may not further distribute the material or use it for any profit-making activity or commercial gain

- You may freely distribute the URL identifying the publication in the public portal 


\title{
Microstructural Characterization of Ni/YSZ Electrodes in a Solid Oxide Electrolysis Stack Tested for 9000 Hours
}

\author{
M. Trini ${ }^{\mathrm{a}}$, P. S. Jørgensen ${ }^{\mathrm{a}}$, A. Hauch ${ }^{\mathrm{a}}$, M. Chen ${ }^{\mathrm{a}}$, P. V. Hendriksen ${ }^{\mathrm{a}}$ \\ ${ }^{a}$ Department of Energy Conversion and Storage, Technical University of Denmark, \\ Roskilde, Dk-4000, Denmark
}

\begin{abstract}
The effects of long-term operation in electrolysis mode on the microstructure of Ni/YSZ electrodes were investigated. The electrode structures were investigated in "as reduced" state and after $9000 \mathrm{~h}$ of operation in a 25 cell stack. Microstructural data were obtained by scanning electron microscopy and focused-ionbeam serial sectioning. Microstructural characteristics were extracted by 1D and 3D methods. Significant microstructural changes were observed between the two cells analyzed. A significant loss of $\mathrm{Ni}$ in the active electrode is observed, from $29 \%$ (by volume) in the reference cell to $\sim 24 \%$ as well as a coarsening of the Ni particle sizes. The long-term tested cell shows lower percolating triple phase boundary density $\left(0.76 \mu \mathrm{m} / \mu \mathrm{m}^{3}\right)$ than the un-tested reference $\left(2.0 \mu \mathrm{m} / \mu \mathrm{m}^{3}\right)$. This reduction is mainly due to the loss of triple phase boundary percolation through the $\mathrm{Ni}$ phase where a reduction from a percolation degree above $90 \%$ to $\sim 50 \%$ is observed.
\end{abstract}

\section{Introduction}

The interest in utilizing solid oxide cells for electrolysis purpose has increased during the last decade (1). In the electrolysis process electrical energy is converted into chemical energy that can be stored as $\mathrm{H}_{2}$ or in the case of co-electrolysis of steam and $\mathrm{CO}_{2}$ as synthesis gas $\left(\mathrm{CO} / \mathrm{H}_{2}-\right.$ mixture $)(2,3)$. This option is attractive in energy scenarios where non-programmable energy sources, such as wind and solar, are dominant sources of electricity. The need to demonstrate long-term durability is one of the critical issues currently limiting the introduction of the technology. 5-10 years of operational life is required to make the technology competitive $(4,5)$. In addition, high current density during SOECs operation is of importance to improve overall process economy.

The operating temperature of solid oxide cells (SOCs) is around $700-850^{\circ} \mathrm{C}$. One and the same cell can be operated in both fuel cell mode and electrolysis mode. This is an attractive characteristic of the technology as it increases the number of hours where operation of the SOEC/SOFC-plant is economically attractive in an energy system dominated by fluctuating production. To increase the penetration of intermittent energy sources (e.g. wind and solar power) cost and efficiency of the electrical energy storage (EES) are key points. When an electricity overproduction takes place, the surplus can be converted to fuel (hydrogen or hydrocarbons), which can be applied in the transport sector or stored and used later when demand for electricity increases $(6,7)$. 
The SOEC cell performance is strongly affected by materials and operating conditions. Ni-YSZ cermets are extensively used for SOC fuel electrode and to improve electrode performance and durability an understanding of the microstructural changes occurring in these under specific operating conditions is of fundamental importance. To correlate any observed electrical degradation with associated microstructural changes a full microstructural characterization of the three main components ( $\mathrm{Ni}, \mathrm{YSZ}$ and pores) is required.

Coarsening of the Ni particles in the Ni-YSZ composite electrodes in solid oxide fuel cells is considered one of the main causes of fuel electrode degradation $(8,9)$. This process occurs when Ni particles are agglomerating during the operation. Several studies have been carried out to explain and model the process $(8,9)$. The changes in the Niphase in Ni-YSZ composite electrodes have been described with simplified Fick's law type descriptions $(8,9)$. The differences in surface energy are considered the driving force behind the coarsening and surface diffusion is dominating the transport $(8,9)$. Smaller Ni particles are incorporated by the bigger ones leading to an overall reduction in the number of particles and an increase in the size of single particles. Several studies have established that Ni-coarsening is a main contributing factor to the "fast initial" electrical degradation often observed over the first 1000-4000 hours of cell test (time scale depends on temperature and polarization) $(8,9)$.

Numerous studies have been carried out on microstructural characterization of $\mathrm{Ni}$ YSZ electrodes, but most of these have focused on degradation in fuel cell mode. In (10) Thydén et al. address the problem of lacking contrast between Ni and YSZ at SEM acceleration voltages in the $10-20 \mathrm{keV}$ range. They analyzed a non-coated sample by combining low-voltage images recorded with field emission SEM (FE-SEM) secondary electron detector and an in-lens detector. The developed methodology allows clear identification of percolating $\mathrm{Ni}$ versus non-percolating $\mathrm{Ni}$, the YSZ phase and the pores. This imaging technique was adopted by Hauch et al. in (11), where the effects of different sintering temperatures on the SOFC anode were analyzed in terms of phase fraction and particle intercept length. Low voltage in-lens and backscattered SEM images were used for the analysis proposed by Mogensen et al. in (12) on Ni-particles shape and $\mathrm{Ni}$ migration in the $\mathrm{pH}_{2} \mathrm{O}$ gradient established during polarization. The structure both at fuel inlet and outlet was investigated.

In order to reconstruct a 3D volume of a Ni/YSZ electrode, the FIB-SEM technique has been used extensively $(13,14,15)$. Particular attention has been given to the continuous particle size distribution (16) and the triple phase boundary (TPB) in terms of length, tortuosity and "critical pathways" (13). A microstructural analysis of SOECs tested up to $1500 \mathrm{~h}$ through image analysis and 1D mean intercept length (MIL) measurements has been presented in (17) and (18).

Compared to the previously mentioned works, this study focuses on the active fuel electrode of a solid electrolysis cell after $9000 \mathrm{~h}$ of operation in a stack. The quantification of microstructural changes in a SOEC stack after such long operation time is new. In addition, image analyses on micrographs obtained with an energy selective backscattered (ESB) detector was carried out. The microscope settings with low voltage $(2.5 \mathrm{kV})$ and high current $(20 \mathrm{nA})$ provide good contrast between the three phases of interest (i.e. Ni, YSZ and pore) and less image artefacts. The technique allows a quantitative microstructural analysis. 1D MIL ("mean intercept length") measurements were performed on the images and the phase fraction of the three phases was determined through these measurements. Moreover, a semi-automated segmentation process was applied to reduce the uncertainty of segmentation in the presence of image artefacts. 
Nevertheless, parameters such as particle size and information on TPB percolation cannot be obtained through this analysis without assumptions. Also, a more elaborate 3D reconstruction analysis was carried out based on the 570 FIB-SEM sections obtained. This provides information on particle size distribution (PSD) and pathway connectivity in each phase and importantly does not require any assumptions on particle shape to be made.

\section{Experimental and Methodology}

An SOEC stack, with 25 identical cells of $87.7 \mathrm{~cm}^{2}$ active area stacked with coated Crofer interconnects was analyzed. The stack was produced by Topsoe Fuel Cell A/S. The cells are of the fuel electrode supported type with a Ni-YSZ support layer and fuel electrode, a YSZ electrolyte, and a LSCF-CGO (LSCF: (La,Sr)(Co,Fe)O $\mathrm{O}_{3-\delta}$, CGO:(Ce, Gd $\left.) \mathrm{O}_{2}\right)$ oxygen electrode. There is a CGO barrier layer between the electrolyte and the oxygen electrode (19).

\section{0 h Stack Test}

The $9000 \mathrm{~h}$ stack test was performed at European Institute for Energy Research (EIFER) and has been described in (19). The stack temperature during the test was recorded by 4 thermocouples: two placed on the gas inlet side and other two on the gas outlet side. The temperature is calculated by evaluating the mean value between the four temperature measurements. The temperature set up was periodically regulated in order to keep an average value of $750^{\circ} \mathrm{C}$ during the entire test (19).

With the aim of keeping the steam conversion constant and equal to $50 \%$ any increase in current was combined with a steam flow increase. Air flow was kept constant during the test and equal to $28 \mathrm{Nl} / \mathrm{min}$. An evaporation unit (FuelCon) was used for steam production. Before feeding the steam into the cell it was mixed with hydrogen $(90 \%$ steam $/ 10 \%$ Hydrogen). The first 2175 hours of test were performed with a current density of $-0.57 \mathrm{~A} / \mathrm{cm}^{2}$ and a hydrogen flow of $1.95 \mathrm{Nl} / \mathrm{min}$. For the following 4785 hours the stack was operated at $-0.72 \mathrm{~A} / \mathrm{cm}^{2}$. Then a DC power supply breakdown occurred; the test was re-started for 350 hours at $-0.57 \mathrm{~A} / \mathrm{cm}^{2}$ and then brought again at $-0.72 \mathrm{~A} / \mathrm{cm}^{2}$ for the rest of the test. More details about the test and stack performance during operation can be found in (19).

$\underline{1 D \text { Analysis }}$

After the test, the stack was embedded in epoxy and split in two. The lower part (from cell 11 to cell 25) was further cut and six samples of interest were obtained as shown in Figure 1 


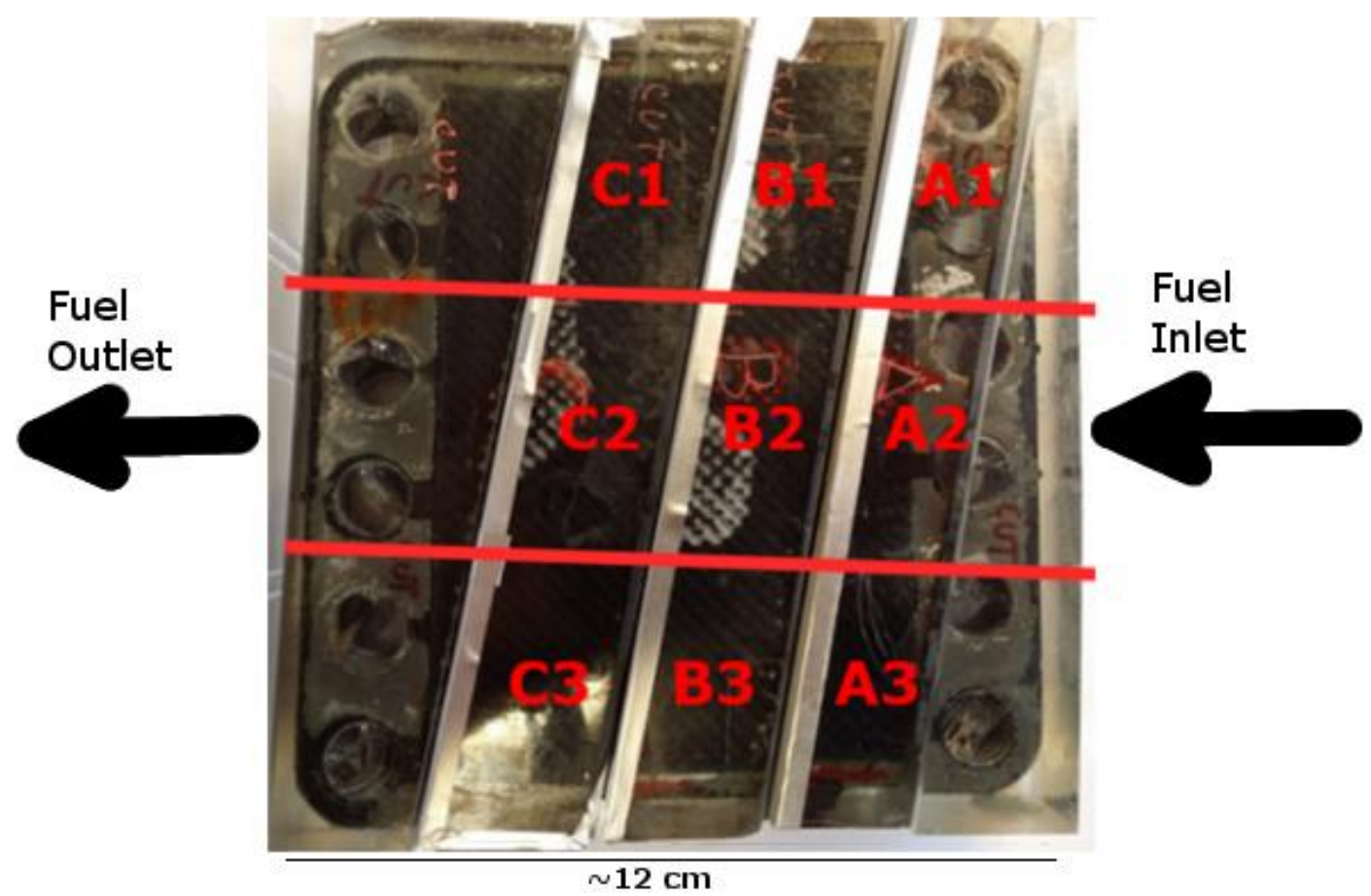

Figure 1. Schematic illustration of SEM sample preparation on the SOEC stack cross section. A1, A2, A3 are on the fuel/steam inlet side, while $\mathrm{C} 1, \mathrm{C} 2, \mathrm{C} 2$ are close to the fuel outlet side.

Both fuel inlet and outlet sites (i.e. A2 and C2 cross sections) were investigated in the $1 \mathrm{D}$ analysis of the fuel electrode. Four locations of interest were analyzed, two on each of the samples: 1) directly under the contact point between the cell and the IC, and 2) at the middle of a gas channel. The area in which the cell is directly in contact with the IC is of particular interest because this is where the local current density is expected to be the highest. Due to several sample preparation processes carried out on the stack and with the aim of analyzing the same cell on both inlet and outlet side, cell number $17^{\text {th }}$, counting from the top of the stack, has been chosen for this study. For comparison, also a "reference cell" (i.e. a cell from the same production batch but not long term tested) was analyzed. The reference cell was reduced at $1000^{\circ} \mathrm{C}$ for 2 hours in moisturized $9 \% \mathrm{H}_{2}$ in $\mathrm{N}_{2}$ with $\sim 4 \%$ of steam.

Due to the close backscatter coefficients of Ni and YSZ at 10-20 kV (10) acceleration voltage, the contrast between the two phases is too low to perform a high-quality automated segmentation for further analysis $(13,20,21)$. Moreover, the pore size tends to be underestimated at high accelerating voltage due to a high penetration depth that results in a signal being obtained from solid structures beneath the thin layer of epoxy resin. The use of an ESB detector at low voltage and high current $(2.5 \mathrm{kV}$ and $20 \mathrm{nA}$, respectively) on the other hand provides good information on the sample structure. The working distance used was $3.9 \mathrm{~mm}$ and a value of $1.5 \mathrm{kV}$ was set for the filtering grid that prevents the detection of secondary electrons. This result in high contrast enabling the three phases to be distinguished and a semi-automated segmentation can be performed.

ESB detector images, like the one shown in Figure 2a) for the reference cell, were recorded along the electrolyte with a short distance between images using a Zeiss Merlin microscope. The overall length covered and used for this analysis is $\sim 300 \mu \mathrm{m}$ per sample. 
The active electrode thickness is $\sim 10 \mu \mathrm{m}$. In order to investigate the microstructure inside the active fuel/steam electrode, the analysis was done in the central $8 \mu \mathrm{m}$ of the electrode (i.e. starting from $\sim 1 \mu \mathrm{m}$ away from the electrolyte into the fuel electrode and terminating $\sim 1 \mu \mathrm{m}$ before reaching the support layer). 10 lines with a spacing of $\sim 0.8$ $\mu \mathrm{m}$ were drawn in the eight $\mu \mathrm{m}$ of interest in order to perform the segmentation. In this analysis all the particles crossed by each line are included even if more lines cross the same particle in different points.

The good contrast obtained by this microscope methodology allows processing the micrographs with the "ManSeg" software (22). Based on regional intensity along a line on the image, the program computes the intensity gradient and suggests phase interface locations at locations of local gradient maxima. The decision to classify a location as an interface is performed manually. This technique is less prone to image artefacts than an automated segmentation approach and avoids human bias by only allowing interface locations at local maxima in the intensity gradient. More than 1000 particles were included in the analysis in order to reduce the confidence intervals and obtain smoother distributions (i.e. either Ni, YSZ or pores). Data obtained are the lengths of the particles of each phase, which can be post-processed in order to evaluate the phase fractions (Equation 1) and the mean intercept length (Equation 2) of each phase

$$
\begin{gathered}
\mathrm{PF}_{\mathrm{i}}=(\text { overall length phase })_{\mathrm{i}} /\left(\sum_{\mathrm{i}}(\text { overall length phase })_{\mathrm{i}}\right) \\
\mathrm{MIL}_{\mathrm{i}}=\left(\sum_{\mathrm{k}} \mathrm{l}_{\mathrm{k}}\right) / \mathrm{k}
\end{gathered}
$$

Where the subscript $i$ is the $i^{\text {th }}$ phase (Ni, YSZ and pores), $k$ is the total amount of segments recorded for the phase $i$ and $l_{k}$ is the length of the $k^{\text {th }}$ segment.

The ease of this 1D analysis from 2D micrograph data allows investigations at different locations of interest. The standard deviation (std) of the MIL data for each phase was estimated through the "bootstrapping" statistical method (23). In order to investigate more complex aspects of the microstructural changes a 3D microstructural characterization of the most relevant regions was also performed.

\section{$\underline{\text { 3D Analysis }}$}

3D image data were collected by FIB serial sectioning with a Zeiss XB1540 Crossbeam microscope on the reference cell and on one location of interest in the tested cell (i.e. inlet side directly under the IC contact point with the cell). The acquisition of inlens (located in the beam path) and SE2 (Everhart-Thornley) detector images was performed simultaneously with a voxel resolution of $25 \times 25 \times 35.6 \mathrm{~nm}^{3}$. A sub-volume of $501 \times 321 \times 570$ pixels $\left(12.5 \times 8 \times 20 \mu \mathrm{m}^{3}\right)$ was selected from each dataset starting from $\sim 1 \mu \mathrm{m}$ away from the electrolyte and extending into the electrode parallel to the electrolyte. The slice direction was along the electrolyte as described in (13). In-lens and SE2 images were used together for the segmentation of the two datasets acquired. The two volumes, having the same size and placed in the same location with respect to the electrolyte, were then processed and segmented using the method described in (13). This technique is much more time consuming than the 1D analysis and for this reason the number of sites that can be analyzed in practice is limited. However, once the segmented 3D data are obtained, the same line intercept measurement performed on the low voltage SEM images can be automatically performed and the results can be compared with those obtained by the semi-automated/manual 1D segmentation performed on the $2 \mathrm{D}$ data. 
The particle size distribution (16) was used to quantify the distribution of particle sizes in each phase. This method calculates the distribution of the largest spheres that can fit inside each part of a structure. The spheres used for the PSD computation are evaluated for each of the 2D section composing the FIB serial sections: the largest circle that fits the particle in the 2D section is "extended" to a 3D sphere. The TPB critical pathway diameter (13) was used to analyze the bottlenecks of the transport pathways through each phase. The analysis was performed from all 6 directions (i.e. $\mathrm{X}, \mathrm{Y}$ and $\mathrm{Z}$ in both ways).

\section{Results and Discussion}

\section{$\underline{\text { Results of 1D Measurements }}$}

The cell under analysis has been manufactured starting from a Ni/YSZ ratio of 40/60 vol\%, the minimum porosity estimated for this composition is $\sim 22 \%$ in agreement with the results of the analysis performed. The phase fractions and the MIL for each phase in all the investigated sections are presented in Table I, where A2 and C2 denote inlet and outlet with respect to fuel flow and IC and ${ }_{\mathrm{GC}}$ indicate the contact point with the IC and the gas channel, respectively. The MIL value is expressed as mean and standard deviation obtained with the bootstrapping statistical method (23). The biggest difference is observed between the reference cell and the location at the contact point with the IC in the tested cell. The biggest microstructural difference is here intended as the changes in $\mathrm{Ni}$ phase fraction and particles MIL obtained through the analysis of 2D SEM micrographs. Figure 2 shows two micrographs and relative phase fraction and MIL quantification for these two extreme cases.

TABLE I. 1D intercept length results: phase fraction and MIL expressed as mean and standard deviation.

\begin{tabular}{ccccccc}
\hline Location & \multicolumn{3}{c}{ Phase fraction [\%] } & \multicolumn{3}{c}{ MIL $[\boldsymbol{\mu m}]$} \\
\hline Ni & YSZ & Pores & Ni & YSZ & Pores \\
\hline Reference & 34 & 44 & 22 & $1.06 \pm 0.02$ & $1.04 \pm 0.02$ & $0.56 \pm 0.01$ \\
$\mathrm{~A} 2_{\mathrm{IC}}$ & 27 & 41 & 32 & $1.45 \pm 0.04$ & $0.97 \pm 0.02$ & $0.79 \pm 0.02$ \\
$\mathrm{~A} 2_{\mathrm{GC}}$ & 28 & 37 & 35 & $1.30 \pm 0.03$ & $0.93 \pm 0.02$ & $0.91 \pm 0.02$ \\
$\mathrm{C} 2_{\mathrm{IC}}$ & 31 & 40 & 29 & $1.35 \pm 0.03$ & $1.01 \pm 0.02$ & $0.74 \pm 0.02$ \\
$\mathrm{C} 2_{\mathrm{GC}}$ & 31 & 37 & 32 & $1.33 \pm 0.03$ & $0.92 \pm 0.02$ & $0.81 \pm 0.02$ \\
\hline
\end{tabular}


a)

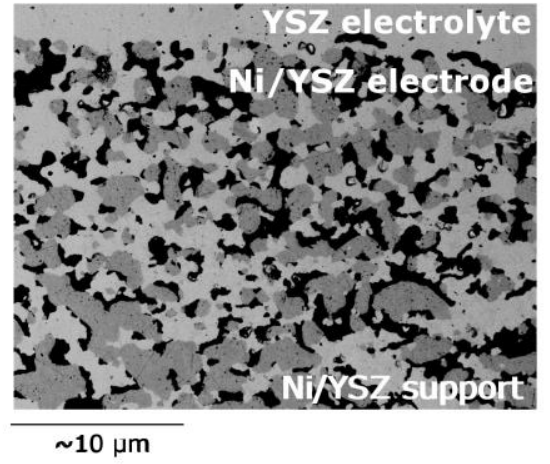

b)

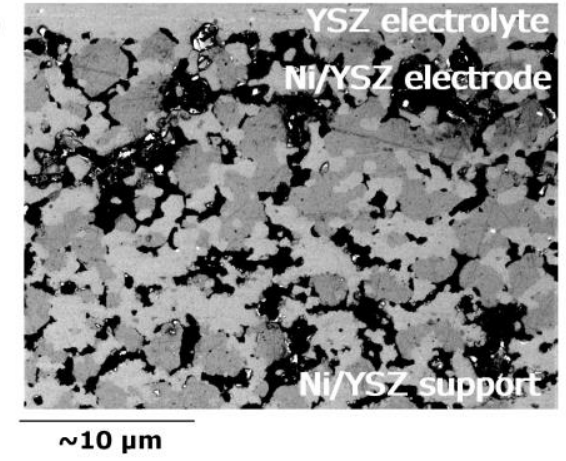

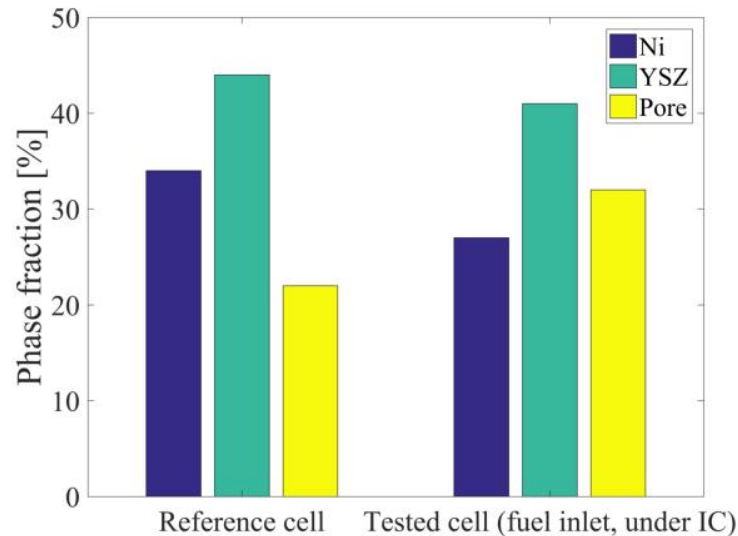

c)

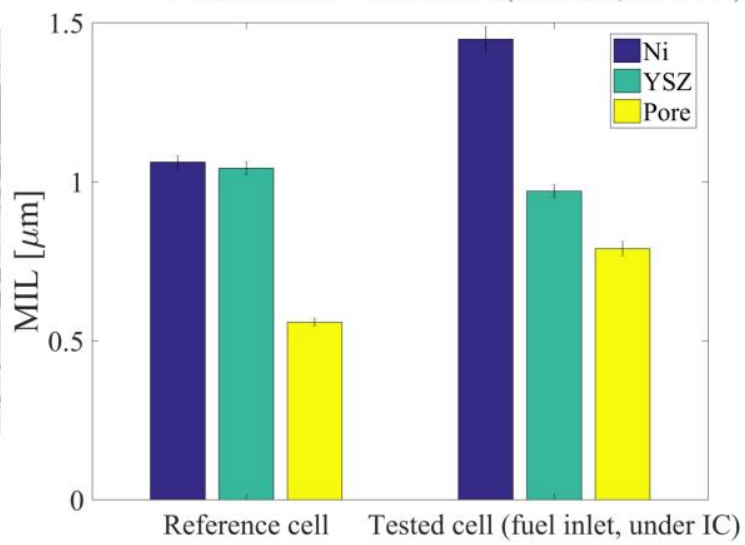

d)

Figure 2. On the right: selected SEM images of the Ni-YSZ electrodes in the reference cell (a) and the $9000 \mathrm{~h}$ tested cell (b). On the left: relative quantification of phase fractions (c) and mean intercept length (d) from 1D analysis. In (a) and (b), light gray = YSZ, dark gray $=\mathrm{Ni}$ and black $=$ pores .

The results from the 1D analysis have been analyzed also in terms of particle size distributions based on intercept length measurements, the bin size in the histograms was chosen to be $40 \mathrm{~nm}$ and a smoothing average filter over 12 bins was applied. The results of the analysis normalized with respect to the bin size are shown in Figure 3. 

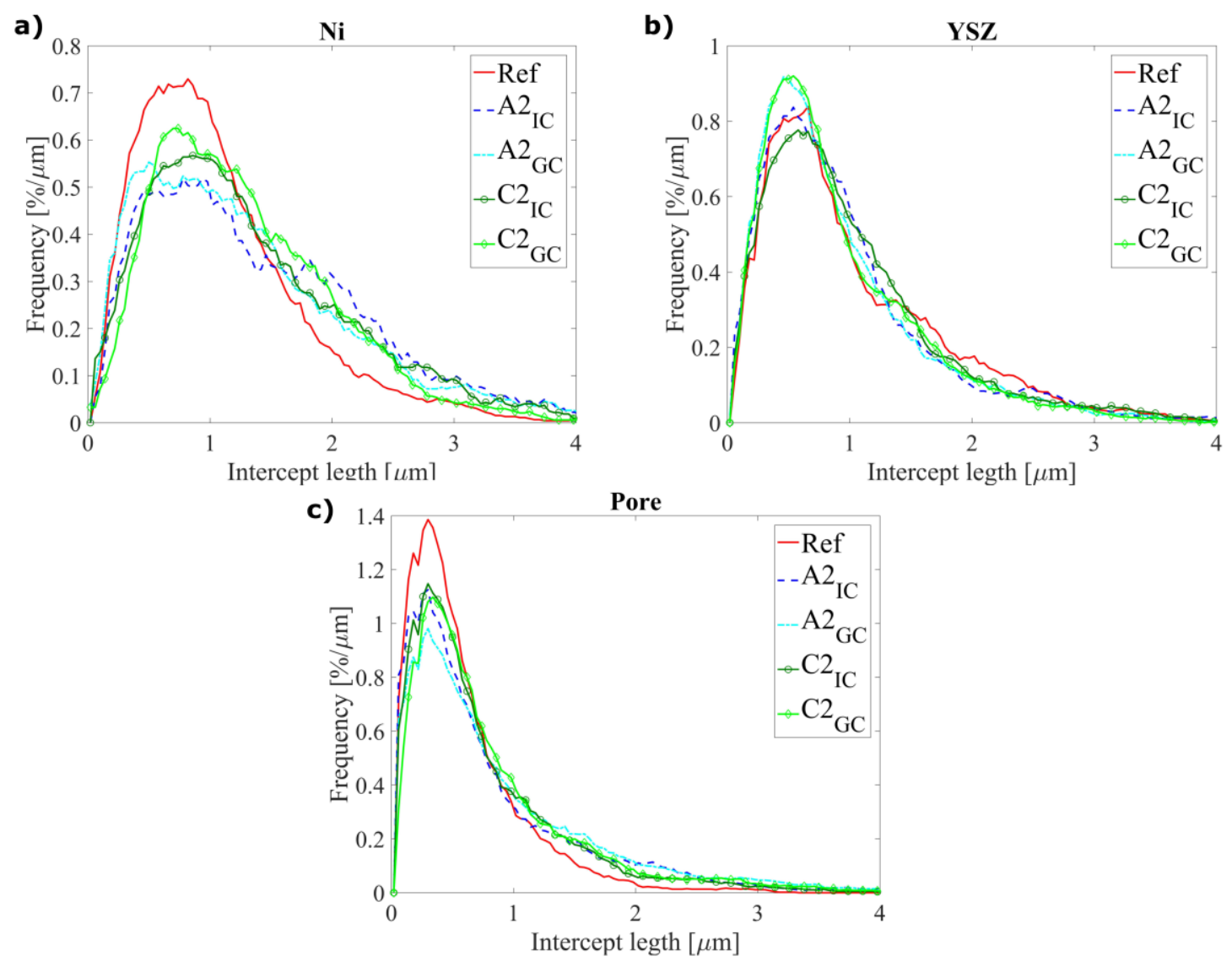

Figure 3. Ni (a), YSZ (b) and pore (c) 1D particle size distributions based on the line intercept method measured in the active fuel electrode for an overall length of $\sim 300 \mu \mathrm{m}$ for each region investigated.

\section{$\underline{\text { Results of 3D Measurements }}$}

As observed in Figure 3, the most evident difference in the results is between the reference cell and the location under the IC at the inlet side of the tested cell. For this reason those two points were selected for a $3 \mathrm{D}$ reconstruction by FIB serial sectioning. A surface rendering of the two segmented volumes is illustrated in Figure 4. In this figure the electrolyte is located above both volumes as indicated. Table II shows phase fractions as well as total and percolating TPB density calculated on the segmented volumes. The results are obtained as the average of TPB length measurements computed for the 6 directions of the volume. 

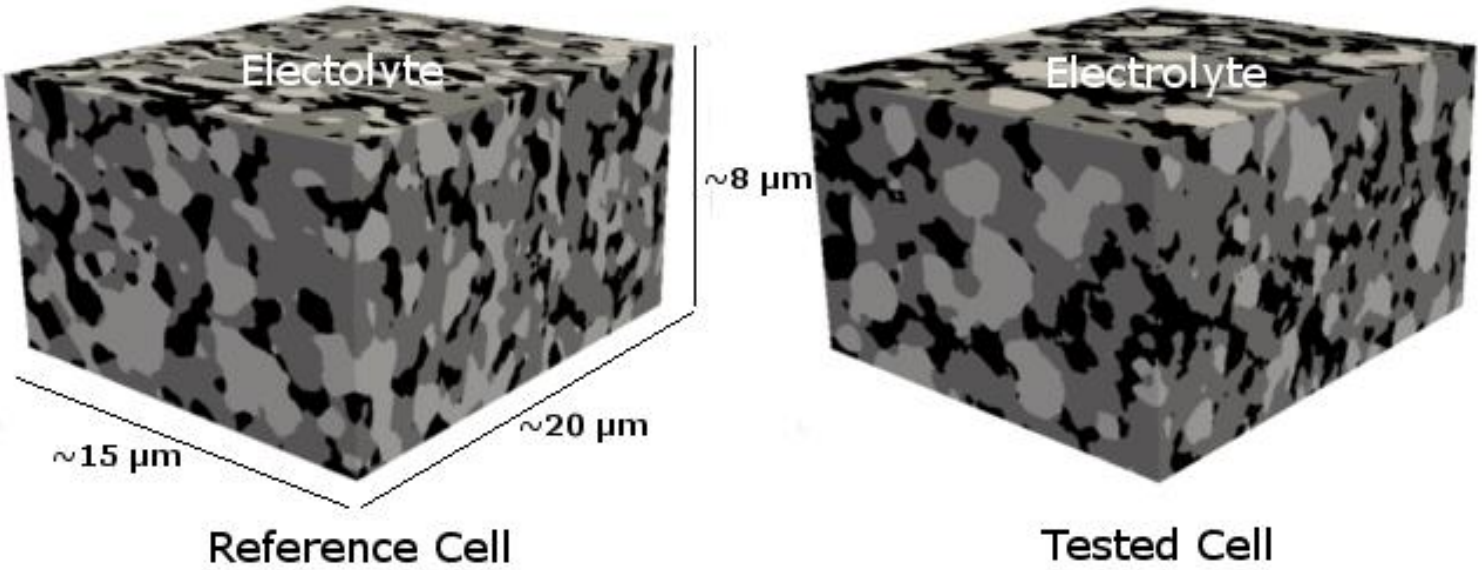

Figure 4. Segmented 3D image data: dark gray $=$ YSZ, light gray $=$ Ni and black $=$ pores

TABLE II. Phase fraction of the 3D segmented volumes.

\begin{tabular}{cccccc}
\hline Location & \multicolumn{3}{c}{ Phase fraction [\%] } & Total TPBs $\left[\boldsymbol{\mu \mathbf { m }} / \boldsymbol{\mu m}^{3}\right]$ & $\begin{array}{c}\text { Percolating TPBs } \\
{\left[\boldsymbol{\mu m} / \boldsymbol{\mu m}^{3}\right]}\end{array}$ \\
\hline & $\mathbf{N i}$ & YSZ & Pores & & \\
\hline Reference & 29 & 46 & 25 & 2.40 & 2.00 \\
A2 $2_{\mathrm{IC}}$ & 24 & 47 & 29 & 1.40 & 0.76 \\
\hline
\end{tabular}

The results of the continuous particle size distributions and the TPB critical pathway diameter are shown in Figure 5. The calculation of the TPB critical pathways radius is described in (13). This parameter gives information on the dimensions of the network structure of the TPB by calculating the radius of the largest particles that can pass through the network structure to a TPB site. The TPB critical pathway results are averages of the results from the 6 directions of the volume. It is expected that the YSZ PSD is not strongly affected by the testing and provides the backbone inside which $\mathrm{Ni}$ coarsens. This behavior is well reproduced by the method implemented here to evaluate the PSD as shown in Figure 5.

a)

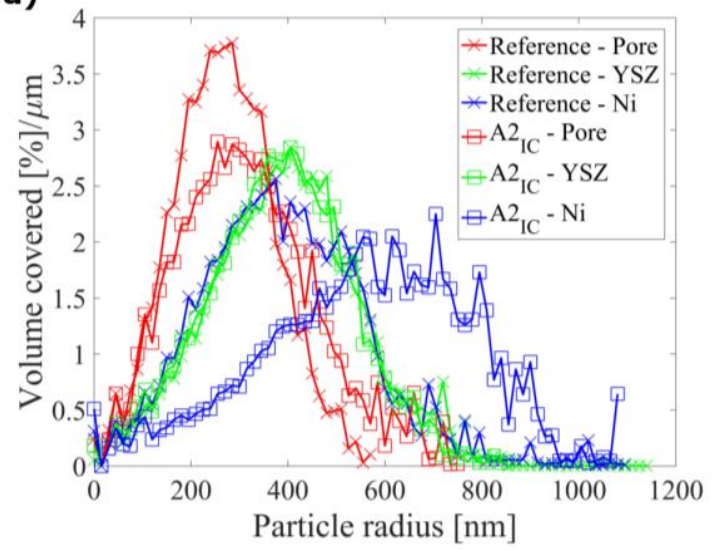

b)

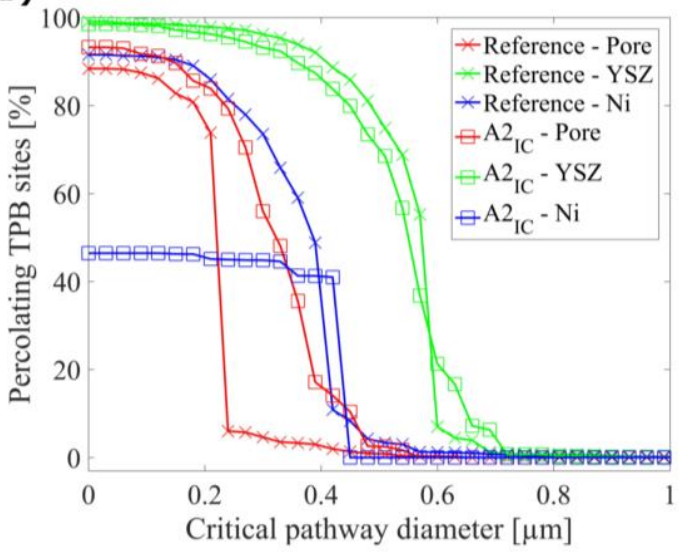

Figure 5. Continuous PSDs (a) and percolating TPB sites (b) extracted from the 3D volumes for the three phases in the reference (x marked) and tested (squared marked) cell. 
The same 1D line intercept analysis performed on the SEM with a low voltage ESB detector was done on some slices of the segmented volumes. The length covered in the $1 \mathrm{D}$ analysis performed on the 3D data was almost the same as the $1 \mathrm{D}$ analysis performed on the SEM micrographs $(\sim 300 \mu \mathrm{m}$ vs $\sim 340 \mu \mathrm{m})$. More than 1000 particles of either Ni, YSZ or pores were crossed to obtain robust statistics. Phase fractions and MILs for each of the three phases in each sample were analyzed. Results are summarized in Table III. For what concerns the 3D segmented volumes, the $1 \mathrm{D}$ measurements are recorded in 2 different directions (vertical $\sim 8 \mu \mathrm{m}$ and horizontal $\sim 20 \mu \mathrm{m}$ direction in Figure 4).

TABLE III. Phase fraction and MIL obtained by 1D analysis on images extracted from the 3D volumes.

\begin{tabular}{|c|c|c|c|c|c|c|}
\hline \multirow[t]{2}{*}{ Location } & \multicolumn{3}{|c|}{ Phase fraction [\%] } & \multicolumn{3}{|c|}{ MIL $[\mu \mathrm{m}]$} \\
\hline & $\mathbf{N i}$ & YSZ & Pores & $\mathbf{N i}$ & YSZ & Pores \\
\hline Reference & 30 & 46 & 24 & $1.03 \pm 0.02$ & $1.18 \pm 0.01$ & $0.76 \pm 0.01$ \\
\hline $\mathrm{A} 2 \mathrm{IC}_{\mathrm{IC}}$ & 23 & 48 & 29 & $1.39 \pm 0.03$ & $1.23 \pm 0.01$ & $0.91 \pm 0.02$ \\
\hline
\end{tabular}

Concerning the phase fraction an additional investigation was performed by evaluating the phase fractions as a function of the distance from the electrolyte. The results are illustrated in Figure 6. In this figure the electrolyte is located on the left side of each graph in correspondence to a YSZ phase fraction of $100 \%$ and the total distance taken into account is approx. $18 \mu \mathrm{m}$. The two vertical dashed lines define the region of the analyzed 3D volumes. The squared markers show the slices of the $3 \mathrm{D}$ volume used for the 1D line intercept measurements along the vertical $8 \mu \mathrm{m}$ with reference to Figure 4 .
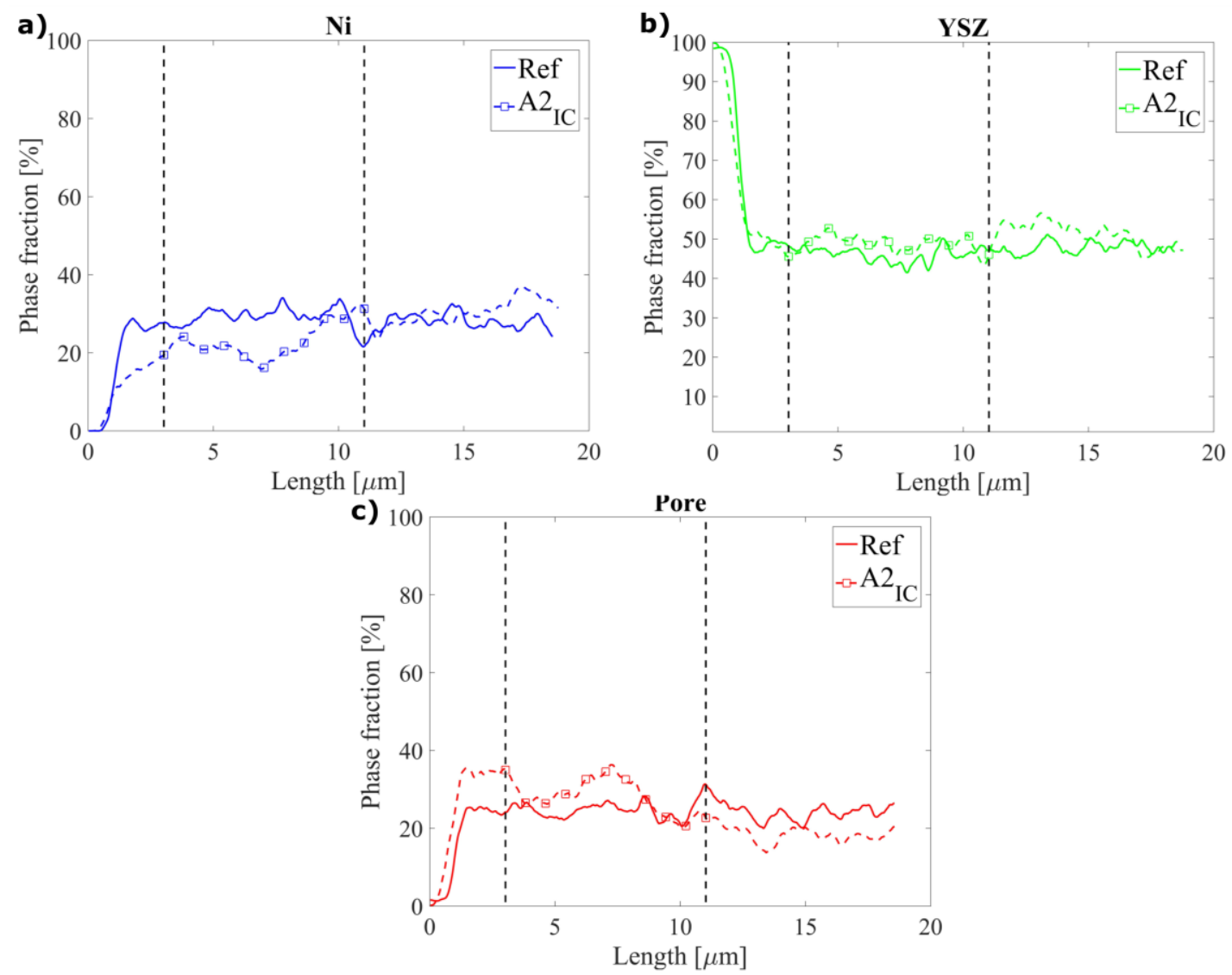

Figure 6. Ni (a), YSZ (b) and pore (c) phase fraction as a function of the distance from the electrolyte. 
In Figure 6, the area of interest for the investigation performed is characterized by a lowering of $\mathrm{Ni}$ content and an increase in porosity after the testing while the YSZ is not substantially affected by the operation. Opposite trends for $\mathrm{Ni}$ and pores are observed by going deeper into the support layer, i.e. the Ni content is increased and the porosity decreased.

The phase fraction evaluation was performed through three different approaches: line intercept on SEM images (polished cross section), segmentation of FIB serial sectioning and finally by line intercept measurements on the segmented volumes. The three methods show some difference in the phase fraction quantification but the trends between the reference and tested cell are consistent between the three methods: A general decrease in $\mathrm{Ni}$ content in the inner $\sim 20 \mu \mathrm{m}$ of the electrode on the tested cell compared to the reference one is observed. This is particularly evident by the 1D measurements reported in Table I (34\% of Ni in the reference cell and $29 \%$ in the tested one) and Table III (30\% of $\mathrm{Ni}$ in the reference cell and $23 \%$ in the tested one). More attenuated changes are observed in the 3D analysis as summarized in Table II: $29 \%$ in the reference cell versus $24 \%$ in the tested one. Uncertainty on the calculation of the phase fraction can be due to several factors: intrinsic differences of the methods applied, human bias in the segmentation process performed on the data. In order to compare the continuous PSD computed on the 3D segmented volumes and the 1D line intercept measurements, the 3D PSD is plotted in Figure 7 together with the equivalent sphere volume coverage computed with 1D measurements. The volume coverage based on $1 \mathrm{D}$ measurements is calculated by considering the diameter of each sphere equals to the measured intercept length of the relative particle. Each distribution is normalized to sum to $100 \%$ for each phase. Results in Figure 7 refer both to 1D measurements recorded on low voltage SEM images and on 1D measurements on slices of the 3D segmented volumes. 
a)

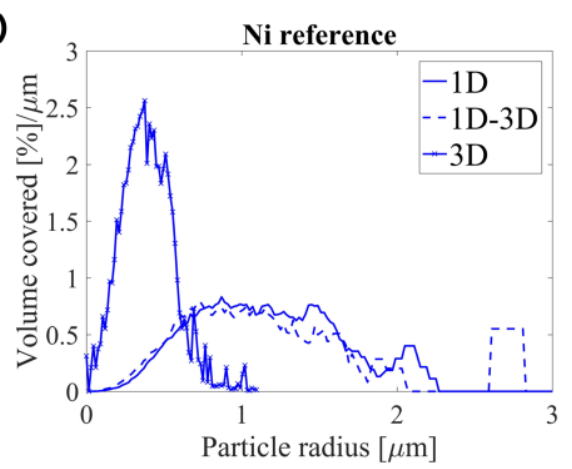

c)

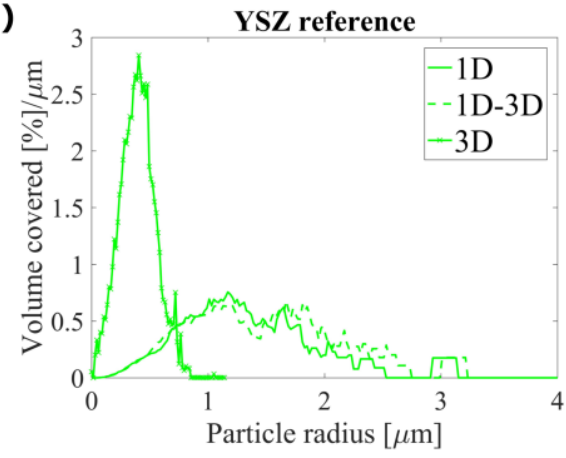

e)

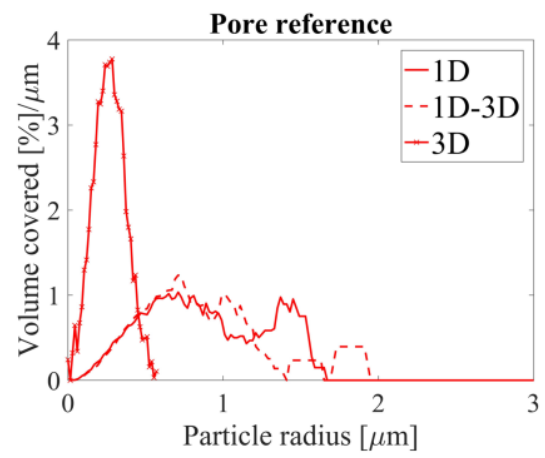

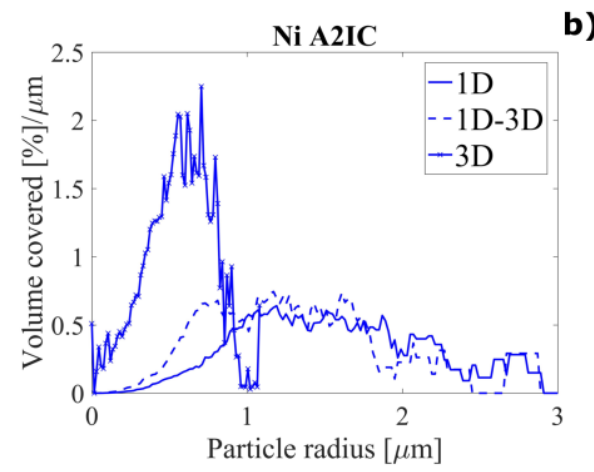
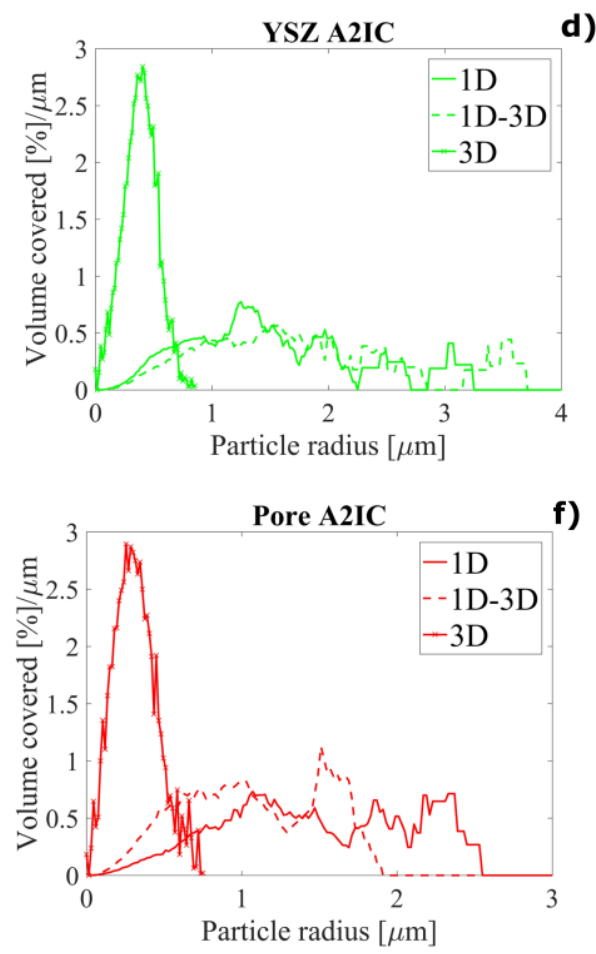

Figure 7. Comparison between continuous PSDs obtained from 3D data, 1D measurements on low voltage SEM ESB detector images and 1D measurements on slices of the segmented volumes (1D-3D) for the three phases in the reference (a, c and e) and tested cell (b, $d$ and $f)$.

Figure 7 aims to illustrate the difference in measurements methods adopted in this paper (i.e. 1D and 3D). The issue of relating the line intercept length with a PSDs is illustrated here by interpreting this value as the particle diameter. Large values of intercept length result in big volumes covered by single particles without taking into account the effective tube-like shape of them. In some of the graphs in Figure 7 the rare large values are excluded to make the comparison between reference and tested cell more understandable.

\section{Electrode Microstructural Changes During Operation}

Both the 1D measurements and those derived from 3D analyses highlight the same qualitative trends in terms of phase fractions and particles size distribution in the active 
fuel electrode. The unexpected significant differences recorded for YSZ phase fraction in Table I can be due to a significant uncertainty in this quantification. The results obtained by $3 \mathrm{D}$ analysis in Table II well represent the expected phase fraction changes after the long-term operation of the cell. In fact, it is expected that the YSZ structure does not change significantly over time and for this reason also the YSZ content should be almost constant after long-term testing. By considering the Ni migration phenomenon and that the YSZ structure and volume is stable in the electrode, the porosity in the tested cell is expected to increase as a consequence. Data in Table II well represents these expectations: While the YSZ content is almost unvaried between the reference (46\%) and the tested cell (47\%) and $\mathrm{Ni}$ content is decreased in the active fuel electrode from $29 \%$ (reference cell) to $24 \%$ (tested cell), the porosity increases. The path and transport mechanism for the Ni migration is still not unambiguously determined, a hypothesis on the process has been presented in (12), where a loss on $\mathrm{Ni}$ in the layer closes to the electrolyte was observed and explained through $\mathrm{Ni}$ migration via $\mathrm{Ni}(\mathrm{OH})_{\mathrm{x}}$ complexes. Also in the present case local differences are observed for the four regions analyzed. The most significant change is recorded in the $\mathrm{A} 2 \mathrm{IC}_{\mathrm{IC}}$ location, where there is a high electrochemical activity and consequently significant gradients in the gas-phase exist.

On the local scale of the two datasets obtained by $3 \mathrm{D}$ reconstructions, Figure 6a) is helpful in order to understand the migration of $\mathrm{Ni}$ away from the electrode layer closest to the electrolyte. $\mathrm{Ni}$ is significantly reduced after the testing in the $\sim 10 \mu \mathrm{m}$ active fuel electrode, where the region is marked by dashed lines in the graphs of Figure 6. Figure $6 \mathrm{~b})$ confirms the previous data proving that the YSZ percentage in the two volumes analyzed is stable and not significantly affected by the long term testing. As a consequence the pore fraction shows an opposite trend with respect to the one of the $\mathrm{Ni}$, Figure 6c).

During the long term testing the $\mathrm{Ni}$ particle size shows a significant increase as illustrated in Figure 3a), Figure 5a) and Figure 7a) and b). In particular, both Figure 3a) and Figure 5a) show a clear shift of intercept lengths and continuous PSD towards higher values, respectively. Moreover, the peaks show an enlargement: while the intercept length peak shifts from $\sim 0.6 \mu \mathrm{m}$ to $\sim 0.7-1.1 \mu \mathrm{m}$ in the tested one, the shift observed in the continuous PSD is from $\sim 0.4 \mu \mathrm{m}$ to $\sim 0.6-0.8 \mu \mathrm{m}$, the discrepancy between $1 \mathrm{D}$ and 3D measurements is further described in the next paragraph. The reported shifts illustrate that the rate of the $\mathrm{Ni}$ coarsening process $(8,24)$ is significant under conditions here applied. The average size of the pores increases during operation primarily as a consequence of Ni-redistribution. The YSZ structure does not change significantly over the test period. Both of these effects are illustrated in Figure 3 and Figure 5a). For the YSZ the differences between the reference and the tested cell are in-significant compared to the uncertainty. Changes on line intercept measurements in the pores are also observed, with a reduction of the peak height in correspondence of $\sim 0.5 \mu \mathrm{m}$ and an increase in the number of pores with a length intercept in the range of $\sim 1-2 \mu \mathrm{m}$.

The electrode performance of a Ni-YSZ electrode is strongly affected by the accessible TPB. The electrochemical reactions take place only at the percolating TPBs sites where the three phases $\mathrm{Ni}, \mathrm{YSZ}$ and pores can carry/conduct the reactants (electrons, oxide ions and steam, respectively). The TPB length is reduced from $2.4 \mu \mathrm{m} / \mu \mathrm{m}^{3}$ in the reference cell to $1.4 \mu \mathrm{m} / \mu \mathrm{m}^{3}$ in the tested one. Considering the percolating TPB only the reduction is from $\sim 2 \mu \mathrm{m} / \mu \mathrm{m}^{3}$ in the reference to $\sim 0.76 \mu \mathrm{m} / \mu \mathrm{m}^{3}$ in the tested electrode. This microstructural change most likely contributes to observed degradation in electrical performance over the test (19). 
Figure 5b) shows the critical pathways radius analysis of the reference and tested cell. Not many studies on tested SOEC report estimations of TPBs density, in particular for long-term testing. In (25) a SOEC tested for $\sim 1300 \mathrm{~h}$ is analyzed (more details on the cell test can be found in (26)), the total amount of TPBs is reported to be $1.61 \mu \mathrm{m} / \mu \mathrm{m}^{3}$ and only $1.30 \mu \mathrm{m} / \mu \mathrm{m}^{3}$ are percolating. More data can be found in the literature for SOFC, since the initial structure (i.e. the one of the reference cell) is similar for SOFC and SOEC after the reduction of the $\mathrm{NiO}$, a comparison with other non-tested cell can be performed. In (13) a TPBs study of 2 SOFCs reduced at different temperatures was performed: 4.5 $\mu \mathrm{m} / \mu \mathrm{m}^{3}$ and $4.7 \mu \mathrm{m} / \mu \mathrm{m}^{3}$ total TPBs, and $3.5 \mu \mathrm{m} / \mu \mathrm{m}^{3}$ and $3.9 \mu \mathrm{m} / \mu \mathrm{m}^{3}$ percolating TPBs were found for cells reduce at $1000^{\circ} \mathrm{C}$ and $840^{\circ} \mathrm{C}$, respectively. The figure shows that $90 \%$ of the TPBs are percolating through the $\mathrm{Ni}$ phase for the reference cell while only $50 \%$ after long-term testing. This demonstrates that changes in the Ni phase is the main contributor to the reduction in percolating TPB length. A comparison between the two cells can be performed by assuming, for instance, that a high performing (low resistance) $\mathrm{Ni}$ network requires that Ni particles are networking with a radius of at least $200 \mathrm{~nm}$. In the reference cell $\sim 85 \%$ of the TPBs reached via such a Ni network will be available for reaction while in the inlet part of the long-term tested cell it amounts to only $50 \%$. It means that not only has the cell lost percolating TPBs in the $9 \mathrm{kh}$ testing but the "quality" of the network to the TPBs has also changed significantly.

\section{$\underline{1 \mathrm{D} \text { and } 3 \mathrm{D} \text { Results }}$}

The Ni and YSZ 3D network structure inside a SOC can be considered "tube-like"; composed by overlapping spheres of different diameters. It is challenging to apply the principle of a particle size distribution to this type of structure, as it is not trivial what constitutes a particle and how the size is defined. The line intercepts (1D) and the continuous PSD (3D) are very similar in how they define the size. The continuous PSD measures the size of the largest sphere that can fit completely inside a given structure and the line intercept measures the size of the largest line segment (1D generalization of a sphere). The differences between the two methods arise from the number of constraining dimensions. The continuous PSD is constrained in all three dimensions and the line intercept length is only constrained in one dimension. In particular, for cylinder structures this means that the line intercept measurements will sometimes be made along the length of the cylinder, while the continuous PSD is constrained by the diameter of the tube and thus always measures the diameter. The line intercept measurements are thus for a given structure, where some of the particles are tube like or elongated expected to result in larger apparent diameters than the continuous PSD, well in line with what we find here. The algorithm of how to derive a PSD from data of a segmented structure is described in (16).

In Figure 3, line intercept data are presented in terms of frequency while in Figure 7 the volume coverage of equivalent spheres with a certain radius is illustrated to be comparable to the continuous PSD. It is evident that the continuous PSD and the line intercept results are not directly comparable due to the differences in the constraint of the measurements. The $1 \mathrm{D}$ results are significantly shifted towards larger measurements due to some measurements being made along the length of cylinder like structures rather than across (as discussed above). However, the line intercept measurements made from the polished cross sections and from the segmented 3D data show similar distributions. Some differences are still observed especially for the left tail of the distributions where fewer small particles are observed for the 1D on low voltage SEM images compared to the 1D 
from the segmented 3D volume. This is most likely due to the increased accuracy that can be obtained through automated segmentation implemented for the volumes rather than the semi-automated process applied on the polished low voltage SEM micrographs. The different polishing methods (mechanical vs. FIB milling) can also introduce minor systematic differences due to uneven polishing depth in different phases and mechanical removal of small particles near the surface during polishing.

The continuous PSD can be automatically computed on 3D segmented volumes and provides additional information about the connectivity of the phase networks (e.g. percolated TPB). Nevertheless, the image data used to perform the 1D measurements are significantly faster to collect than the 3D data and can quickly be made across a large area of the cell. The combination of the two methods (both 3D and 1D) has several benefits. 1) It allows the formation of a link between the local 3D and non-local 2D data by comparing $1 \mathrm{D}$ measurements and thus test the assumption of non-local microstructure homogeneity for the 3D analysis. 2) It forms a link between the basic information obtained from the 1D measurements and the more detailed information obtained through the 3D measurements. 3) It provides validation and a sanity check of both methods by comparing the same measurement performed on data collected by different methods.

\section{Conclusions}

A detailed 1D and 3D microstructural characterization of an SOEC electrode before and after 9000 hours of operation in a stack is presented in this work. The Ni phase shows significant differences between the reference and tested cell in terms of phase fraction and particles size in the active electrode. $29 \%$ of $\mathrm{Ni}$ was observed in the reference cell with 3D measurements and a total content of $24 \%$ was recorded after the testing with the same analysis technique. Concerning the particle size, the MIL increased from $\sim 1 \mu \mathrm{m}$ to $\sim 1.45 \mu \mathrm{m}$, as determined through a 1D analysis, while the peak in the particles radius calculated by the continuous PSD method on the 3D data shifted from $\sim 400 \mathrm{~nm}$ to $\sim 600$ $\mathrm{nm}$. A reduction in TPB percolation through the Ni phase in the tested cell compared to the reference cell confirms that the cell microstructure is degraded by the $9000 \mathrm{~h}$ of operation. The discrepancy between the measures deduced from the local 3D data and the $1 \mathrm{D}$ analyses are due to the differences in number of constraining parameters used in the two analysis methods. The study provides a relation between information gained from the different approaches (1D versus 3D) and a validation of both the methods. The 3D data allows an accurate analysis of a local volume (e.g. yielding both PSD and information about total TPB and fraction of percolating TPB) but the data is time consuming to obtain and analyze.

\section{Acknowledgments}

This work was financially supported by the project "Synfuel" (4106-00006B) from Innovation Fund Denmark. Moreover, the authors would like to thank senior development engineer Janet Jonna Bentzen, senior researcher Jacob R. Bowen and Haldor Topsøe A/S for their technical support. 


\section{References}

1. M. A. Laguna-Bercero, J. Power Sources, 203, 4 (2012).

2. D. Simwonis, F. Tietz, D. Stöver, Solid State Ionics, 132, 241 (2000).

3. A. Brisse, J. Schefold and M. Zahid, Int. J. Hydrogen Energy, 33, 5375 (2008).

4. S. D. Ebbesen, C. Graves, A. Hauch, S. H. Jensen, and M. Mogensen, J. Electrochemical Society, 157, B1419 (2010).

5. Q. X. Fu, C. Mabilat, M. Zahid, A. Brisse, and L. Gautier, Energy Environ. Sci., 3, 1328 (2010).

6. C. H. Wendel, P. Kazempoor, R. J. Braun, J. Power Sources, 276, 133 (2015).

7. S. H. Jensen, C. Graves, M. Mogensen, C. Wendel, R. Bran, G, Hughes, Z. Gao, S. A. Barnett, Energy \& Environmental Science, 8, 2471 (2015).

8. S. Gao, J. Li, Z. Lin, J. Power Sources, 255, 144 (2014).

9. R. Vaßen, D. Simwonis, D. Stöver, J. Materials Science, 36, 147 (2001).

10. K. Thydén, Y.L. Liu, J. B. Bilde-Sørensen, Solid State Ionics, 178, 1984 (2008).

11. A. Hauch, C. Birkl, K. Brodersen, P.S. Jørgensen, 10th European SOFC Forum, A1007 (2012).

12. M. B. Mogensen, A. Hauch, X. Sun, M. Chen, Y. Tao, S. D. Ebbesen, P. V. Hendriksen, 12th European SOFC \& SOEC Forum, A0902 (2016).

13. P.S. Jørgensen, S. L. Ebbehøj, A. Hauch, J. Power Sources, 279, 686 (2015).

14. T. Shimura, Z. Jiao, S. Hara, N. Shikazono, J. Power Sources, 267, 58 (2014).

15. P.S. Jørgensen, K. V. Hansen, R. Larsen, J. R. Bowen, J. Microsc., 244, 45 (2011).

16. B. Münch, L. Holzer, J. American Ceramic Society, 91, 4059 (2008).

17. M. Chen, Y.L. Liu, J. J. Bentzen, W. Zhang, X. Sun, A. Hauch, Y. Tao, J.R. Bowen, P.V. Hendriksen, J. The Electrochemical Society, 160 (8), F883 (2013).

18. A. Hauch, K. Brodersen, M. Chen, M. B. Mogensen, Solid State Ionics, 293, 27 (2016).

19. A. Brisse, J. Schefold, G. Core, Q. Fu, 11th European SOFC \& SOEC Forum, B1405 (2014).

20. S. Primdahl, M. Mogensen, J. Applied Electrochemistry, 30, 247 (2000).

21. K. R. Lee, S. H. Choi, J. Kim, H. W. Lee, J. H. Lee, J. Power Sources, 140, 226 (2005).

22. J. R. Bowen, ManSeg, Data Analysis Software, Ver 0.36VW (2014)

23. B. Efron, R. Tibshirani, Statistical Science, 1, 54 (1986)

24. P. Tanasini, M. Cannarozzo, P. Costamagna, A. Fase, J. Van Herle, A. HesselerWyser, C. Comninellis, Fuel Cells, 9, 740 (2009)

25. P. S. Jørgensen, J. R. Bowen, ECS Trans., 35(1), 1655 (2011).

26. A. Hauch, S. D. Ebbesen, S. H. Jensen, M. B. Mogensen, J. Electrochemical Society, 155, B1184 (2008) 